\title{
INDUCTION OF ANESTHESIA IN CORONARY ARTERY BYPASS GRAFT SURGERY:THE HEMODYNAMIC AND ANALGESIC EFFECTS OF KETAMINE
}

\author{
Elif Basagan-Mogol, Suna Goren, Gulsen Korfali, Gurkan Turker, Fatma Nur \\ Kaya
}

doi: $10.1590 / \mathbf{S 1 8 0 7 - 5 9 3 2 2 0 1 0 0 0 0 2 0 0 0 0 3 ~}$

Basagan-Mogol E, Goren S, G Korfali, Turker G, Kaya FN. Induction of anesthesia in coronary artery bypass graft surgery: THE hemodynamic and analgesic effects of ketamine. Clinics. 2010;65(2):133-8.

OBJECTIVE: The aim of this prospective, randomized study was to evaluate the hemodynamic and analgesic effects of ketamine by comparing it with propofol starting at the induction of anesthesia until the end of sternotomy in patients undergoing coronary artery bypass grafting surgery.

INTRODUCTION: Anesthetic induction and maintenance may induce myocardial ischemia in patients with coronary artery disease. A primary goal in the anesthesia of patients undergoing coronary artery bypass grafting surgery is both the attenuation of sympathetic responses to noxious stimuli and the prevention of hypotension.

METHODS: Thirty patients undergoing coronary artery bypass grafting surgery were randomized to receive either ketamine 2 mg.kg-1 (Group K) or propofol 0.5 mg.kg-1 (Group P) during induction of anesthesia. Patients also received standardized doses of midazolam, fentanyl, and rocuronium in the induction sequence. The duration of anesthesia from induction to skin incision and sternotomy, as well as the supplemental doses of fentanyl and sevoflurane, were recorded. Heart rate, mean arterial pressure, central venous pressure, pulmonary arterial pressure, pulmonary capillary wedge pressure, cardiac index, systemic and pulmonary vascular resistance indices, stroke work index, and left and right ventricular stroke work indices were obtained before induction of anesthesia; one minute after induction; one, three, five, and ten minutes after intubation; one minute after skin incision; and at one minute after sternotomy.

RESULTS: There were significant changes in the measured and calculated hemodynamic variables when compared to their values before induction. One minute after induction, mean arterial pressure and the systemic vascular resistance index decreased significantly in group $\mathrm{P}(\mathrm{p}<0.01)$.

CONCLUSION: There were no differences between groups in the consumption of sevoflurane or in the use of additional fentanyl. The combination of ketamine, midazolam, and fentanyl for the induction of anesthesia provided better hemodynamic stability during induction and until the end of sternotomy in patients undergoing coronary artery bypass grafting surgery.

KEYWORDS: Coronary artery bypass grafting; Ketamine; Propofol; Fentanyl; Midazolam.

\section{INTRODUCTION}

Induction of anesthesia in patients with heart disease is hazardous because the impaired circulatory system is less tolerant of depression. ${ }^{1}$ The primary goal during coronary

Uludag University School of Medicine, Department of Anesthesiology and Reanimation - Bursa, Turkey

Email: basagan@uludag.edu.tr

Tel.: 902244428039

Received for publication on October 26, 2009

Accepted for publication on November 03, 2009 artery bypass grafting (CABG) surgery is attenuation of sympathetic responses to noxious stimuli, such as laryngoscopy, intubation, skin incision, sternal splitting, and spreading. Hypotension caused by vasodilation and cardiac depression due to anesthetic drugs should also be avoided. No single anesthetic agent is suitable for all CABG patients, and many drug combinations have been used to achieve hemodynamic stability.

Following induction and intubation, the anesthetic course is typically characterized by an initial period of minimal stimulation that is frequently associated with hypotension, 
followed by periods of intense stimulation, such as skin incision and sternotomy, that can produce tachycardia and hypertension; anesthetic agents should be used appropriately in anticipation of these events. ${ }^{1,2}$ The dissociative agent ketamine is a potent analgesic at sub-anesthetic plasma concentrations, with an elimination half-life of $2.17 \mathrm{~h}$ in patients who were not premedicated. It elevates arterial blood pressure, pulmonary artery pressure, and heart rate due to sympathetic stimulation. Benzodiazepines, the most effective agents for attenuating these cardiovascular effects, cause an increase in plasma ketamine levels and prolong the redistribution and elimination half-lives. ${ }^{3,4}$ There is no clear consensus as to the use of ketamine in any combination for patients undergoing CABG surgery. Some studies found it to be satisfactory, ${ }^{5-7}$ while others fail to confirm this finding. ${ }^{8-10}$ The aim of this study was to evaluate the hemodynamic and analgesic effects of ketamine, as compared with propofol, when used for induction of anesthesia in patients undergoing elective CABG surgery.

\section{MATERIALS AND METHODS}

After obtaining approval of the Ethics Committee of the Hospital as well as the written informed consent of all study participants, thirty patients between the ages of 35 and 75 who were grades three and four based on the Classification of the American Society of Anesthesiologists and who were scheduled for elective CABG surgery were enrolled in this study. All patients who participated in this prospective study had good left ventricular function (left ventricular ejection fraction $>40 \%$; left ventricular end-diastolic pressure $<15$ $\mathrm{mmHg}$ ). Patients with valvular disease, diabetes mellitus, misuse of alcohol or drugs, or severe hepatic and renal insufficiency, as well as those who were undergoing a reoperation, were excluded.

All patients continued their medications up to the day of surgery and were pre-medicated with intramuscular morphine at $0.1 \mathrm{mg} \cdot \mathrm{kg}^{-1}$ one hour before surgery. Hemodynamic monitoring consisted of a fivelead electrocardiogram, radial artery cannulation, and a pulmonary artery catheter (Baxter Healthcare Corp., Irvine, CA, USA) placed through the right internal jugular vein. All catheters were inserted before the induction of anesthesia, under local anesthesia and sedation, with a total dose of $0.07 \mathrm{mg} . \mathrm{kg}^{-1}$ midazolam. Heart rate (HR), systolic arterial blood pressure (SAP), diastolic arterial blood pressure (DAP), mean arterial blood pressure (MAP), central venous pressure (CVP), mean pulmonary artery pressure (PAP), mean pulmonary capillary wedge pressure (PCWP), and cardiac output $(\mathrm{CO})$ were measured. $\mathrm{CO}$ was measured using the mean of the three values obtained by the thermodilution technique. The cardiac index (CI), the stroke volume index (SVI), the left and right ventricular stroke work indices (LVSWI and RVSWI), the systemic vascular resistance index (SVRI), and the pulmonary vascular resistance index (PVRI) were calculated from the standard formulae. ST-segment analysis and trending were monitored. A positive deflection of $2 \mathrm{~mm}$ or a negative deflection of $1 \mathrm{~mm}$ indicated myocardial ischemia.

The data were measured at: (T1) before induction of anesthesia, (T2) one minute after induction, (T3) one minute after intubation, (T4) three minutes after intubation, (T5) five minutes after intubation, (T6) ten minutes after intubation, (T7) one minute after skin incision, and (T8) one minute after sternotomy.

After catheterization, the first hemodynamic measurements were completed in $15 \mathrm{~min}$, after which anesthesia was administered. Patients were randomized to receive either ketamine (Group K) or propofol (Group P) using a computer-generated table of random numbers. For induction, fentanyl $5 \mu \mathrm{g} \cdot \mathrm{kg}^{-1}$ was given to both groups over 30 s. In group $K(n=15)$, patients were induced with ketamine (Ketalar®, Eczacibasi, Luleburgaz, Turkey) $2 \mathrm{mg} \cdot \mathrm{kg}^{-1}$, which was injected over $30 \mathrm{~s}$. In group $\mathrm{P}(\mathrm{n}=15)$, propofol (Propofol 1\% Fresenius, Fresenius Kabi Deutschland, Bad Homburg, Germany) $0.5 \mathrm{mg} \cdot \mathrm{kg}^{-1}$ was injected into a freely running infusion of saline solution over $30 \mathrm{~s}$. If this approach was not sufficient, additional $10 \mathrm{mg}$ boluses were administered every $10 \mathrm{sec}$ until there was loss of the eyelash reflex. Rocuronium (0.6 mg. $\left.\mathrm{kg}^{-1}\right)$ was given over five seconds to both groups. Measurements were started one minute after the injection of rocuronium during mask ventilation with $100 \%$ oxygen and took $45 \mathrm{sec}$ to complete. Tracheal intubation was performed two minutes after rocuronium administration. The durations of laryngoscopy and intubation were recorded. Patients breathed $100 \%$ oxygen throughout the induction sequence, and ventilation was assisted manually when necessary. After intubation, the lungs were ventilated with an air-oxygen mixture $\left(\mathrm{FIO}_{2}\right.$ 0.6) using a ventilator (Cato, Draeger, Lübeck, Germany) adjusted to give an arterial $\mathrm{PCO}_{2}$ of $4.7-5.3 \mathrm{kPa}$. Anesthesia was maintained with $0.5-2 \%$ sevoflurane, and additional rocuronium and fentanyl were administered as necessary. The end-expiratory sevoflurane concentration was adjusted according to clinical responses, such as hypertension ( $20 \%$ increase from baseline), hypotension (20\% decrease from baseline), tachycardia (20\% increase from baseline), bradycardia ( $20 \%$ decrease from baseline), lacrimation, movement, grimacing, eye opening, or coughing. The duration of anesthesia from induction to skin incision and sternotomy, as well as any supplemental doses of fentanyl were recorded. The amount of sevoflurane in milliliters used was measured after completion of each study period by refilling the 
vaporizer, which initially had been completely full. The observer who recorded all measurements was blinded to the induction agents.

A response to tracheal intubation of an increase in either HR or MAP $>20 \%$ from baseline (T1) was regarded as clinically significant and was treated with intravenous nitroglycerine (0.25-0.5 mg i.v.). For reductions in SAP to less than $90 \mathrm{~mm} \mathrm{Hg}$, the patient was placed in the Trendelenburg position (up to $30^{\circ}$ ), and lactated Ringer's solution (5-7 mg. $\mathrm{kg}^{-1}$ ) was infused. If these interventions were insufficient, inotropic support (dopamine or dobutamine; $5 \mu \mathrm{g} \cdot \mathrm{kg}^{-1} \cdot \mathrm{dk}^{-1}$ ) was begun. When bradycardia occurred $(\mathrm{HR}<40), 0.5 \mathrm{mg}$ atropine was injected. Intravenous fluid infusions were not started until arrival in the operating room and were restricted to less than $1 \mathrm{~L}$ of a crystalloid solution during the study period for all patients.

Statistical analyses were performed with the software package SPSS ${ }^{\circledR}$, version 11.5 (SPSS, Inc, Chicago, IL). Data were presented as mean values \pm standard deviation. Differences from baseline were evaluated by the Wilcoxon signed rank test. Comparison of the percent change values between the groups was performed via a Mann-Whitney U-test and a Kruskal Wallis test when appropriate. A value of $\mathrm{p}<0.05$ was considered significant.

\section{RESULTS}

Preoperative drug therapy and demographic data are listed in Table 1. Patients in the two groups were similar with respect to age, weight, surface area, and gender. There were no episodes of laryngospasm, bronchospasm, chest wall rigidity, excessive secretions, or prolonged ( $>30 \mathrm{~s}$ ) intubation attempts in any patient. The average total period of induction

Table 1 - Baseline demographics and preoperative characteristics of patients

\begin{tabular}{lcc}
\hline & Group K & Group P \\
\hline $\mathrm{N}$ & 15 & 15 \\
Age $(\mathrm{y})$ & $60.3 \pm 2.7$ & $58.8 \pm 2.2$ \\
Weight $(\mathrm{kg})$ & $77.9 \pm 2.5$ & $78.5 \pm 2.9$ \\
Body surface area $\left(\mathrm{m}^{2}\right)$ & $1.87 \pm 0.12$ & $1.88 \pm 0.14$ \\
Sex (F/M) & $4 / 11$ & $3 / 12$ \\
LVEDP (mmHg) & $9.5 \pm 2.9$ & $9.3 \pm 3.1$ \\
Canadian Class II/III/IV & $1 / 10 / 4$ & $5 / 6 / 4$ \\
Medications n $(\%)$ & & \\
Nitrates & $10(66.6 \%)$ & $9(60 \%)$ \\
Beta-blockers & $7(46.6 \%)$ & $3(20 \%)$ \\
Calcium channel blockers & $4(26.6 \%)$ & $1(6.6 \%)$ \\
Anti-hypertensive & $1(6.6 \%)$ & \\
\hline
\end{tabular}

LVEDP: left ventricular end-diastolic pressure. Data are presented as mean \pm SD or number of patients. was 75 seconds.

One patient received an additional $10 \mathrm{mg}$ propofol injection to obtain loss of the eyelash reflex. The endexpiratory sevoflurane concentrations and sevoflurane consumption were similar in both groups (Table 2). The time to the first incision and to sternotomy after induction of anesthesia did not differ between groups (Table 3).

Table 2 - Sevoflurane usage during the study period

\begin{tabular}{lcc}
\hline & Group K (n=15) & Group P (n=15) \\
\hline $\begin{array}{l}\text { End-expiratory sevoflu- } \\
\text { rane concentration (\%) }\end{array}$ & $1.1 \pm 0.04$ & $1.1 \pm 0.06$ \\
$\begin{array}{l}\text { Sevoflurane consump- } \\
\text { tion (mL) }\end{array}$ & $12.4 \pm 1.2$ & $13.1 \pm 1.8$ \\
\hline
\end{tabular}

Data are mean $\pm \mathrm{SD}$

Table 3 - Time to the first incision and sternotomy after the induction

\begin{tabular}{lcc}
\hline & $\begin{array}{c}\text { Time to incision } \\
(\mathrm{min})\end{array}$ & $\begin{array}{c}\text { Time to sternotomy } \\
(\mathrm{min})\end{array}$ \\
\hline Group K $(\mathrm{n}=15)$ & $21.1 \pm 4.3$ & $27.2 \pm 3.6$ \\
Group P $(\mathrm{n}=15)$ & $20.2 \pm 5.2$ & $26.0 \pm 5.6$ \\
\hline
\end{tabular}

Time to incision: Time to the incision after induction. Time to sternotomy: Time to the sternotomy after induction. Data are presented as mean \pm SD.

Hemodynamic changes are summarized in Table 4. There were significant changes in the values of the measured and calculated hemodynamic variables when compared with baseline (T1). The significant changes between the groups were recorded in MAP and SVRI (Fig. 1A-B). At T2, MAP and SVRI in group $P$ decreased significantly more than group $\mathrm{K}(\mathrm{p}<0.01)$. There were no significant changes in HR, PAP, PCWP, PVRI, SVI, LVSWI, and RVSWI at any measurement time between the groups.

There were no significant changes in the ST segment between or within the groups.

Supplemental doses of fentanyl, $1050 \mu \mathrm{g}$ and 1200 $\mu \mathrm{g}$, were administered after skin incision to eight patients in group $\mathrm{K}$ and twelve patients in group $\mathrm{P}$. There was no difference between the groups with respect to the total use of fentanyl. Only one patient in group $\mathrm{K}$ was treated for hypertension one min after intubation; two from group $\mathrm{P}$ were hypotensive after induction. All patients responded to the initial treatments.

\section{DISCUSSION}

This study investigated the hemodynamic and analgesic effects of ketamine $2 \mathrm{mg} \cdot \mathrm{kg}^{-1}$ in combination 
Table 4 - Hemodynamic variables

\begin{tabular}{|c|c|c|c|c|c|c|c|c|}
\hline Groups & $\mathrm{T} 1$ & $\mathrm{~T} 2$ & $\mathrm{~T} 3$ & $\mathrm{~T} 4$ & T5 & T6 & $\mathrm{T} 7$ & $\mathrm{~T} 8$ \\
\hline $\begin{array}{l}\mathrm{HR} \\
\mathrm{P} \\
\mathrm{K} \\
\end{array}$ & $\begin{array}{l}67 \pm 13 \\
72 \pm 13\end{array}$ & $\begin{array}{l}60 \pm 10^{\pi} \\
65 \pm 11^{*}\end{array}$ & $\begin{array}{c}68 \pm 10 \\
70 \pm 8\end{array}$ & $\begin{array}{c}61 \pm 10^{\pi} \\
68 \pm 8\end{array}$ & $\begin{array}{c}62 \pm 8 \\
65 \pm 10^{*}\end{array}$ & $\begin{array}{c}60 \pm 10^{*} \\
62 \pm 9^{\pi}\end{array}$ & $\begin{array}{c}61 \pm 7 * \\
64 \pm 8\end{array}$ & $\begin{array}{l}66 \pm 7 \\
67 \pm 8\end{array}$ \\
\hline $\begin{array}{l}\text { MAP } \\
\mathrm{P} \\
\mathrm{K} \\
\end{array}$ & $\begin{array}{c}88 \pm 15 \\
96 \pm 9 \\
\end{array}$ & $\begin{array}{l}69 \pm 11^{\Uparrow /} \\
89 \pm 14\end{array}$ & $\begin{array}{c}85 \pm 19 \\
104 \pm 18 *\end{array}$ & $\begin{array}{c}78 \pm 16^{*} \\
99 \pm 17\end{array}$ & $\begin{array}{l}74 \pm 14^{\pi} \\
91 \pm 16\end{array}$ & $\begin{array}{l}77 \pm 12^{\pi} \\
88 \pm 14\end{array}$ & $\begin{array}{l}91 \pm 15 \\
98 \pm 18 \\
\end{array}$ & $\begin{array}{l}98 \pm 11 * \\
100 \pm 13 \\
\end{array}$ \\
\hline $\begin{array}{l}\text { CVP } \\
\mathrm{P} \\
\mathrm{K} \\
\end{array}$ & $\begin{array}{l}6.7 \pm 2.9 \\
7.5 \pm 2,7\end{array}$ & $\begin{array}{c}8.3 \pm 1.6^{*} \\
9 \pm 2.6^{*} \\
\end{array}$ & $\begin{array}{c}9.3 \pm 2.8^{\pi} \\
10.4 \pm 2.0^{\pi /}\end{array}$ & $\begin{array}{l}9.3 \pm 2.6^{*} \\
9.4 \pm 2.2^{*}\end{array}$ & $\begin{array}{r}9.4 \pm 2.4^{\pi} \\
9.7 \pm 2.4^{*}\end{array}$ & $\begin{array}{l}8.8 \pm 2.4 * \\
9.7 \pm 2.7 * \\
\end{array}$ & $\begin{array}{c}9.6 \pm 3.2^{*} \\
10.4 \pm 3.4^{*}\end{array}$ & $\begin{array}{l}9.4 \pm 2.1^{\pi} \\
9.6 \pm 3.6 \\
\end{array}$ \\
\hline $\begin{array}{l}\mathrm{PAP} \\
\mathrm{P} \\
\mathrm{K} \\
\end{array}$ & $\begin{array}{l}15 \pm 5 \\
15 \pm 4 \\
\end{array}$ & $\begin{array}{l}17 \pm 4 * \\
18 \pm 4 *\end{array}$ & $\begin{array}{l}17 \pm 4^{*} \\
20 \pm 3^{\pi} \\
\end{array}$ & $\begin{array}{c}17 \pm 4 \\
18 \pm 3 *\end{array}$ & $\begin{array}{c}16 \pm 3 \\
18 \pm 3 *\end{array}$ & $\begin{array}{c}16 \pm 3 \\
17 \pm 3 * \\
\end{array}$ & $\begin{array}{l}17 \pm 3 * \\
19 \pm 4 * \\
\end{array}$ & $\begin{array}{l}17 \pm 3^{*} \\
18 \pm 5^{*}\end{array}$ \\
\hline $\begin{array}{l}\mathrm{PCWP} \\
\mathrm{P} \\
\mathrm{K} \\
\end{array}$ & $\begin{array}{l}11 \pm 4 \\
11 \pm 4 \\
\end{array}$ & $\begin{array}{l}12 \pm 4 \\
13 \pm 3 \\
\end{array}$ & $\begin{array}{l}13 \pm 3 * \\
15 \pm 3 * \\
\end{array}$ & $\begin{array}{l}12 \pm 4 \\
13 \pm 2 \\
\end{array}$ & $\begin{array}{c}11 \pm 3 \\
14 \pm 3 * \\
\end{array}$ & $\begin{array}{l}11 \pm 3 \\
13 \pm 3 \\
\end{array}$ & $\begin{array}{l}13 \pm 3 * \\
15 \pm 3 * \\
\end{array}$ & $\begin{array}{l}13 \pm 3 * \\
14 \pm 5 * \\
\end{array}$ \\
\hline $\begin{array}{l}\mathrm{CI} \\
\mathrm{P} \\
\mathrm{K} \\
\end{array}$ & $\begin{array}{l}2.2 \pm 0.3 \\
2.2 \pm 0.6 \\
\end{array}$ & $\begin{array}{c}2.1 \pm 0.4 \\
1.8 \pm 0.4^{*} \\
\end{array}$ & $\begin{array}{l}2.2 \pm 0.4 \\
1.9 \pm 0.5 \\
\end{array}$ & $\begin{array}{l}2.1 \pm 0.5 \\
1.8 \pm 0.6 \\
\end{array}$ & $\begin{array}{c}1.9 \pm 0.4 \\
1.7 \pm 0.5^{\mathbb{T}} \\
\end{array}$ & $\begin{array}{l}2.0 \pm 0.4 \\
1.6 \pm 0.5^{\pi} \\
\end{array}$ & $\begin{array}{l}2.0 \pm 0.4 \\
1.6 \pm 0.6^{\mathbb{I}}\end{array}$ & $\begin{array}{l}2.0 \pm 0.4 \\
1.9 \pm 0.4 \\
\end{array}$ \\
\hline $\begin{array}{l}\text { SVRI } \\
\mathrm{P} \\
\mathrm{K} \\
\end{array}$ & $\begin{array}{c}2917 \pm 568 \\
3465 \pm 1025 \\
\end{array}$ & $\begin{array}{l}2341 \pm 567 * \\
3658 \pm 1337 \\
\end{array}$ & $\begin{array}{c}2755 \pm 721 \\
3991 \pm 1151 \\
\end{array}$ & $\begin{array}{c}2651 \pm 810 \\
4002 \pm 1153 \\
\end{array}$ & $\begin{array}{c}2664 \pm 809 \\
4042 \pm 1537 \\
\end{array}$ & $\begin{array}{c}2765 \pm 636 \\
4100 \pm 1896 \\
\end{array}$ & $\begin{array}{c}3248 \pm 717 \\
4633 \pm 1947 \pi \\
\end{array}$ & $\begin{array}{c}3540 \pm 851^{\pi} \\
4678 \pm 1030^{\pi} \\
\end{array}$ \\
\hline $\begin{array}{l}\text { PVRI } \\
\mathrm{P} \\
\mathrm{K} \\
\end{array}$ & $\begin{array}{l}141 \pm 98 \\
168 \pm 78 \\
\end{array}$ & $\begin{array}{l}187 \pm 78^{*} \\
234 \pm 99 *\end{array}$ & $\begin{array}{c}160 \pm 66 \\
189 \pm 100 \\
\end{array}$ & $\begin{array}{c}171 \pm 94 \\
217 \pm 103 \\
\end{array}$ & $\begin{array}{c}195 \pm 49 * \\
180 \pm 99 \\
\end{array}$ & $\begin{array}{l}193 \pm 87 * \\
233 \pm 78 * \\
\end{array}$ & $\begin{array}{l}164 \pm 60 \\
220 \pm 90 \\
\end{array}$ & $\begin{array}{c}174 \pm 75 \\
215 \pm 80^{\text {II }} \\
\end{array}$ \\
\hline $\begin{array}{l}\text { SVI } \\
\mathrm{P} \\
\mathrm{K} \\
\end{array}$ & $\begin{array}{l}34 \pm 6 \\
31 \pm 8 \\
\end{array}$ & $\begin{array}{l}37 \pm 7 \\
29 \pm 8\end{array}$ & $\begin{array}{l}33 \pm 5 \\
29 \pm 6\end{array}$ & $\begin{array}{l}35 \pm 7 \\
28 \pm 8\end{array}$ & $\begin{array}{l}32 \pm 5 \\
28 \pm 8\end{array}$ & $\begin{array}{l}37 \pm 5 \\
29 \pm 8\end{array}$ & $\begin{array}{l}32 \pm 6 \\
26 \pm 9\end{array}$ & $\begin{array}{l}32 \pm 6 \\
28 \pm 8\end{array}$ \\
\hline $\begin{array}{l}\text { LVSWI } \\
\mathrm{P} \\
\mathrm{K} \\
\end{array}$ & $\begin{array}{l}36 \pm 6 \\
36 \pm 9\end{array}$ & $\begin{array}{l}28 \pm 8^{\pi} \\
30 \pm 8^{*}\end{array}$ & $\begin{array}{l}32 \pm 9 * \\
34 \pm 10\end{array}$ & $\begin{array}{l}32 \pm 9 * \\
34 \pm 13 \\
\end{array}$ & $\begin{array}{l}27 \pm 8^{\pi} \\
31 \pm 9 \\
\end{array}$ & $\begin{array}{l}30 \pm 7^{\pi} \\
29 \pm 9^{\pi} \\
\end{array}$ & $\begin{array}{c}34 \pm 8 \\
29 \pm 11 *\end{array}$ & $\begin{array}{c}37 \pm 8 \\
28 \pm 9 * \\
\end{array}$ \\
\hline $\begin{array}{l}\text { RVSWI } \\
\mathrm{P} \\
\mathrm{K} \\
\end{array}$ & $\begin{array}{l}9.7 \pm 5.4 \\
3.8 \pm 1.8\end{array}$ & $\begin{array}{c}10.5 \pm 6.3 \\
3.3 \pm 1.5\end{array}$ & $\begin{array}{c}7.0 \pm 2.9 * \\
3.3 \pm 1.4\end{array}$ & $\begin{array}{l}9.3 \pm 3.9 \\
3.2 \pm 1.7\end{array}$ & $\begin{array}{l}7.3 \pm 3.3 \\
2.8 \pm 1.4\end{array}$ & $\begin{array}{c}8.3 \pm 3.6 \\
2.8 \pm 1.4^{*}\end{array}$ & $\begin{array}{l}7.0 \pm 3.7 \\
2.8 \pm 1.5\end{array}$ & $\begin{array}{l}6.9 \pm 5.2^{*} \\
2.6 \pm 1.5^{*}\end{array}$ \\
\hline
\end{tabular}

P: Group P (patients who were given propofol during induction); K: Group K (patients who were given ketamine during induction); HR: heart rate (beat. $\left.\mathrm{min}^{-1}\right)$; MAP: Mean arterial pressure (mmHg); CVP: Central venous pressure (mmHg); PAP: Mean pulmonary artery pressure (mmHg); PCWP: Mean pulmonary capillary wedge pressure $(\mathrm{mmHg})$; CI: Cardiac index $\left(\mathrm{L} \cdot \mathrm{min}^{-1} \cdot \mathrm{m}^{-2}\right)$; SVI: Stroke volume index $\left(\mathrm{ml} . \mathrm{m}^{-2}\right)$; SVRI and PVRI: Systemic and pulmonary vascular resistance indices (dyne.s. $\mathrm{cm}^{-5} \cdot \mathrm{m}^{-2}$ ); LVSWI and RVSWI: Left and right ventricular stroke work indices (g.m.m $\mathrm{m}^{-2}$ ); T1: Prior to induction of anesthesia, while the patient was awake; T2: one minute after induction; T3: one minute after intubation; T4: three minutes after intubation; T5: five minutes after intubation; T6: 10 minutes after intubation; T7: one minute after skin incision; T8: one minute after sternotomy.

* $\mathrm{p}<0.05$ compared with $\mathrm{T} 1 ;$ II $\mathrm{p}<0.01$ compared with $\mathrm{T} 1 ;+\mathrm{P}<0.001$ compared with $\mathrm{T} 1$

with midazolam $0.07 \mathrm{mg} \cdot \mathrm{kg}^{-1}$ and fentanyl $5 \mu \mathrm{g} \cdot \mathrm{kg}^{-1}$, from induction until the end of sternotomy in patients undergoing CABG surgery. The probable length of the ketamine effect is approximately $30 \mathrm{~min}$. Thus, we planned to follow the course of anesthesia until the end of sternotomy, which usually occurs within $30 \mathrm{~min}$. For the control group, we used propofol in combination with an opioid, which has been shown to be suitable for the induction of anesthesia for CABG in patients with both normal and low cardiac output states. ${ }^{11-13}$

A major feature that distinguishes the effects of ketamine from those of other intravenous anesthetics is the increase in blood pressure and heart rate. However, in this study, we observed hypertension only one minute after intubation and did not observe tachycardia. The use of midazolam and fentanyl in combination with ketamine blunted the hemodynamic response to tracheal intubation, but there was no significant decrease in MAP or SVRI, as seen in group P. Induction with ketamine, $2 \mathrm{mg} \cdot \mathrm{kg}^{-1}$, and midazolam, 0.2-0.4 mg.kg-1 ${ }^{-1}$, was associated with a hypertensive and tachycardic response to tracheal intubation in $25 \%$ of cardiac surgical patients ${ }^{14}$; however, this response was only observed in patients who were preoperatively hypertensive. No normotensive patients exhibited a significant hemodynamic response. Opioids were not used during induction. ${ }^{14}$ The study of Gordon et al., ${ }^{9}$ which compared the ketaminemidazolam combination with sufentanil for rapid sequence induction of anesthesia for CABG surgery failed to confirm the hemodynamic stability of ketamine, but they did not add any opioids during induction. ${ }^{9}$ Schulte-Sasse et al. ${ }^{15}$ analyzed six different anesthesia induction procedures, which are as follows: thiopentone, etomidate, ketamine, 
althesin, diazepam, and flunitrazepam in CABG patients. They concluded that none of these procedures was associated with cardiovascular stimulation during laryngoscopy and tracheal intubation.

The significant increase in CVP for both groups following anesthetic induction are consistent with positive pressure ventilation applied by face mask and endotracheal tube after intubation. There were decreases in CI in group $\mathrm{K}$ at five and ten minutes after intubation and after the skin incision. There was a slight decrease in CI in group $\mathrm{P}$ and an insignificantly greater one in group K. Ketamine induction usually increases CI, but the drug can also produce hemodynamic depression during deep anesthesia, when sympathetic responses do not accompany its administration. ${ }^{4}$ The circulatory stimulating effects of ketamine were largely abolished by fentanyl. ${ }^{15}$ Decreases were seen in group $\mathrm{K}$ during skin preparation and draping, where minimal stimulation was applied.

The systemic vascular resistance index did not change significantly within groups at most measurement times, but it remained lower in group P one minute after the induction, as did the MAP. Propofol provides satisfactory anesthesia in patients undergoing CABG surgery, at the cost of decreased SVRI in patients with normal or low cardiac output states in cardiac surgery. ${ }^{11,16}$

During the study period, one group K patient was treated for hypertension after intubation, and two from group $\mathrm{P}$ were treated for hypotension after induction. This latter effect is to be expected, ${ }^{4}$ and the episodes responded to the Trendelenburg position and infusion of $250 \mathrm{~mL}$ lactated Ringer's solution. The patient who required treatment for post-intubation hypertension had a starting MAP $\geq 105 \mathrm{~mm}$ $\mathrm{Hg}$ and had a satisfactory response to i.v. nitroglycerine.

Our ketamine, midazolam, and fentanyl induction regimen is associated with blunting of the cardiovascular response to laryngoscopy and tracheal intubation, without producing a significant fall in arterial pressure and heart rate during the period of minimal stimulation. Similarly, Raza et al. ${ }^{17}$ showed that a combination of ketamine, midazolam, and sufentanil prevented the adverse hemodynamic changes caused by intubation, skin incision, sternotomy, and periaortic dissection during CABG surgery. The addition of an opioid to the ketamine-midazolam combination provided stable hemodynamics. ${ }^{17}$ Interestingly, the use of ketamine did not produce a significant reduction in fentanyl usage.

The absence of bispectral index (BIS) monitoring could be regarded as a limitation of this study. We assessed the adequacy of anesthesia according to clinical responses and subsequently adjusted the sevoflurane concentration. Although the value of BIS monitoring is well known, some authors believe that it does not offer many advantages over the observation of clinical responses with regard to monitoring the depth of anesthesia. ${ }^{18,19}$

The combination of midazolam, fentanyl, and ketamine provided satisfactory induction conditions in patients undergoing $\mathrm{CABG}$ surgery. There were no adverse hemodynamic effects, ST-segment changes, or adverse hemodynamic changes from induction until the end of sternotomy. Although ketamine failed to clearly contribute to the level of analgesia, we consider the combination to be superior to propofol.

\section{REFERENCES}

1. Moffitt EA, Tarhan S, Lundborg RO. Anesthesia for cardiac surgery: principles and practice. Anesthesiology. 1968;29:1181-205.

2. Bondy RJ, Wynands JE. Anesthesia induction and maintenance strategies. In: Estafanous FG, Barash FG, Reves JG. editors. Cardiac Anesthesia: Principles and Clinical Practice. Philadelphia, USA: Lippincott company; 1994. p.221.

3. Reich DL, Silvay G. Ketamine: an update on the first twenty-five years of clinical experience. Can J Anaesth. 1989;36:186-97.

4. Reves JG, Glass PSA, Lubarsky DA. Nonbarbiturate intravenous anesthetics. In: Miller RD, ed. Anesthesia. $5^{\text {th }}$ ed. Philadelphia, Pennsylvania, USA: Churchill Livingstone; 2000. p.228.

5. Kumar SM, Kothary SP, Zsigmund EK. Lack of cardiovascular stimulation during endotracheal intubation in cardiac surgical patients anesthetized with diazepam-ketamine-pancuronium. Clin Ther. 1980;3:43-8.
6. Jackson APF, Dhadphale PR, Callaghan ML, Alseri S. Hemodynamic studies during induction of anesthesia for open-heart surgery using diazepam and ketamine. Br J Anaesth.1978;50: 375-8.

7. Bazaral MG. Con: Ketamine is a useful anesthetic agent for patients undergoing coronary artery bypass surgery. J Cardiothorac Vasc Anesth. 1992;6:248-51

8. Spotoft H, Korshin JD, Bredgaard Sorensen M, Skovsted P. The cardiovascular effects of ketamine used for induction of anesthesia in patients with valvular heart disease. Can Anaesth Soc J. 1979;26:463-7.

9. Gordon AR, O'Connor JP, Ralley FE, Ramsay JG, Malcolm I. Midazolam-ketamine vs sufentanil for rapid sequence induction of anesthesia for CABG surgery. Can J Anaesth. 1990;37:43.

10. Gomez MN, Tinker JH. Pro: Ketamine anesthesia is contraindicated in patients undergoing coronary artery bypass surgery. J Cardiothorac Vasc Anesth. 1992;6:245-7. 
11. Bell J, Sartain J, Wilkinson GAL, Sherry KM. Propofol and fentanyl anesthesia for patients with low cardiac output state undergoing cardiac surgery: comparison with high-dose fentanyl anesthesia. Br J Anaesth. 1994;73:162-6.

12. Manara AR, Monk CR, Bolsin SN, PRYS Roberts C. Total i.v. anesthesia with propofol and alfentanil for coronary artery bypass grafting. Br J Anaesth. 1991;66:716-8.

13. Lehmann A, Zeitler C, Thaler E, Isqro F, Boldt J. Comparison of two different anesthesia regimens in patients undergoing aortocoronary bypass grafting surgery: sufentanil-midazolam versus remifentanilpropofol. J Cardiothorac Vasc Anesth. 2000;14:416-20.

14. Marlow R, Reich DL, Neustein S, Silvay G. Hemodynamic response to induction of anesthesia with ketamine/midazolam. Can J Anaesth. 1991;38:844-8.
15. Schulte-Sasse U, Hess W, Tarnow J. Hemodynamic analysis of 6 different anesthesia induction procedures in coronary surgery patients. Anasth Intensivther Notfallmed. 1982;17:195-200.

16. Gordon PC, Morrell DF, Pamm JD. Total intravenous anesthesia using propofol and alfentanil for coronary artery bypass surgery. $\mathrm{J}$ Cardiothorac Vasc Anesth. 1994;8:284-8.

17. Raza SM, Masters RW, Zsigmond EK. Hemodynamic stability with midazolam-ketamine-sufentanil analgesia in cardiac surgical patients. Can J Anaesth. 1989;36:617-23.

18. Basar H, Ozcan S, Buyukkocak U, Akpinar S, Apan A. Effect of bispectral index monitoring on sevoflurane consumption. Eur $\mathrm{J}$ Anaesthesiol. 2003;20:396-400.

19. Pavlin DJ, Hong Y, Freund PR, Koerschangen ME, Bower JO, Bowdle TA. The eefct of bispectral index monitoring on end-tidal gas concentration and recovery duration after outpatient anesthesia. Anesth Analg. 2001;93:613-9. 